\title{
Tilt-table testing in syncope - our results
}

\section{Lada Bradić' ${ }^{*}$, Marina Mihajlović', Arijana Crevar', Gregor Eder', Kristina Krželj', Tena Jukić', Olvan Bitunjac², Martina Lovrić Benčić'}

'University of Zagreb School of Medicine, University Hospital Centre Zagreb, Zagreb, Croatia

${ }^{2}$ General Hospital "Dr. Josip Benčević", Slavonski Brod, Croatia

\section{RECEIVED:}

September 242017

ACCEPTED:

September 26, 2017
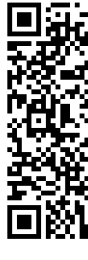

KEYWORDS: tilt-table test, syncope, transient loss of consciousness.
CITATION: Cardiol Croat. 2017;12(9-10):378. I https://doi.org/10.15836/ccar2017.378

*ADDRESS FOR CORRESPONDENCE: Lara Bradić, Klinički bolnički centar Zagreb, Kišpatićeva 12, HR-10000 Zagreb, Croatia. / Phone: +385-91-5794-115 / E-mail: lada.bradic@gmail.com

ORCD: Lada Bradić http://orcid.org/0000-0001-8296-699X • Marina Mihajlović http://orcid.org/0000-0002-0027-9676 Arijana Crevar http://orcid.org/0000-0002-3585-727X • Gregor Eder http://orcid.org/0000-0001-5495-7789 Kristina Krželj http://orcid.org/0000-0003-2269-3138 • Tena Jukić http://orcid.org//0000-0003-2326-1492 Ivan Bitunjac http://orcid.org/0000-0002-4396-6628 • Martina Lovrić Benčić http://orcid.org/0000-0001-8446-6120

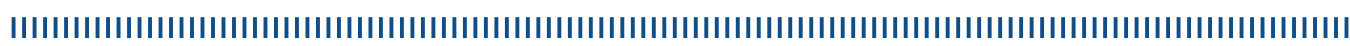

Introduction: Syncope is defined as transient, self-limited loss of consciousness due to temporary global cerebral hypoperfusion, resulting from low peripheral resistance and/or low cardiac output ${ }^{1}$. Reported incidence of syncope is high; 18-40 per 1,000 patient-years in general population ${ }^{2}$. Tilt-table testing enables reproduction and characterization of syncope in controlled settings, according to blood pressure and heart rate response to tilting. Modified VASIS classification to tilt testing distinguishes: reflex/vasodepressor syncope, cardioinhibitory syncope with/without asystole, mixed syncope, orthostatic hypotension and POTS (postural orthostatic tachycardia syndrome)3.

Patients and Methods: We retrospectively analyzed 708 patients (67\% female, 33\% male) who underwent tilt-table testing in our institution from 2013 to September 2017. Of the referred patients 47.6\% were $15-30$ y/o, 29.8\% were 30-60 y/o, and 22.6\% were $>60$ y/o. Patient history included syncope in majority of patients $-84.6 \%, 80.1 \%$ and $68.8 \%$ of patients $<30 \mathrm{y} / 0,30-60 \mathrm{y} / \mathrm{o}$, and $>60 \mathrm{y} / \mathrm{o}$, respectively.

Results: Normal reaction to tilt-up testing was found in $49.3 \%$ of young ( $<30 \mathrm{y} / 0$ ) vs. $83.1 \%$ of elderly patients ( $>60 \mathrm{y} / \mathrm{o}$ ). Tilt-up testing provoked syncope in $32.6 \%$ of patients $<30 \mathrm{y} / \mathrm{o}$ in contrast to $10.9 \%$ of $30-60 \mathrm{y} / 0$ and $11.9 \%$ of patients $>60 \mathrm{y} / \mathrm{o}(\mathrm{p}<0.001)$. Majority of positive results were classified as vasodepressor syncope (54.9\% in patients $<30 \mathrm{y} / \mathrm{o}$ vs. $77.8 \%$ in $>60 \mathrm{y} / \mathrm{o}, \mathrm{p}<0.001)$, cardioinhibitory response was recorded in $10.5 \%$ of patients $<30 \mathrm{y} / \mathrm{o}$ ( $22.2 \%$ of which had asystole), while none of the elderly patients had such type of response ( $p=0.003$ ). Mixed syncope was found in $34.5 \%$ of young ( $<30 \mathrm{y} / \mathrm{o}) \mathrm{vs}$. $22.2 \%$ of elderly $(>60 \mathrm{y} / 0)$ patients, $\mathrm{p}<0.001$.

Conclusion: Our result analysis found majority of positive tilt-table test results in younger patients, while $>83 \%$ of elderly patients had normal reaction to testing, thus questioning widespread use of tilttable testing in this age group. Mechanisms underlying syncope should be sought in order to properly diagnose and counsel patients for syncope avoidance. Only a minority of younger patients had cardioinhibitory syncope, and none during four analyzed years required pacemaker implantation. Elderly patients with syncope should be evaluated using alternative diagnostic algorithms. https://doi.org/10.1016/j.jacc.2011.11.056

2. Olde Nordkamp LR, van Dijk N, Ganzeboom KS, Reitsma JB, Luitse JS, Dekker LR, et al. Syncope prevalence in the ED compared to that in the general practice and population: a strong selection process. Am J Emerg Med. 2009 Mar;27(3):271-9. https://doi.org/10.1016/j.ajem.2008.02.022

3. Simova I. Role of tilt-table testing in syncope diagnosis and management. E-journal of the ESC Council for the Cardiology Practice. 2015 Nov;35(13). Available at: https://www.escardio.org/Journals/E-Journal-of-Cardiology-Practice/Volume-13/role-of-tilt-table-testing-in-syncopediagnosis-and-management (22.9.2017). 